\title{
Representing recovery: how the construction and contestation of needs and priorities can shape long-term outcomes for disaster-affected people
}

\author{
Authors: \\ Roger Few [corresponding author] r.few@uea.ac.uk \\ School of International Development, University of East Anglia, UK \\ Hazel Marsh Hazel.Marsh@uea.ac.uk \\ School of Politics, Philosophy, Language and Communication, University of East \\ Anglia, UK \\ Garima Jain giain@iihs.ac.in \\ Indian Institute for Human Settlements, Bangalore, India \\ Chandni Singh csingh@iihs.ac.in \\ School of Environment and Sustainability, Indian Institute for Human Settlements, \\ Bangalore, India \\ Mark Glyn Llewellyn Tebboth m.tebboth@uea.ac.uk \\ School of International Development, University of East Anglia, UK
}

\section{Funding}

This work was supported by the British Academy's Sustainable Development Programme [award number SDP21100257] 


\title{
Representing recovery: how the construction and contestation of needs and priorities can shape long-term outcomes for disaster-affected people
}

\begin{abstract}
We contend that the representational aspects of recovery play an important but underresearched role in shaping long-term outcomes for disaster-affected populations. Ideas constructed around events, people and processes, and conveyed through discussion, texts and images, are seldom neutral and can be exclusionary in their effect. This review draws insights from literature across multiple disciplines to examine how the representation of needs, roles and approaches to recovery influences the support different social groups receive, their capacities to recover, and their rights and agency. It shows how these representations can be contested and challenged, often by disaster-affected people themselves, and calls for increased attention on how to move creatively toward more informed, inclusive and supportive recovery visions and processes.
\end{abstract}

Keywords: Disaster, Recovery, Representation, Memorialization, Marginalization

\section{Introduction}

The aim of this review paper is to highlight how competing ideas about disaster recovery emerge within society, some gaining traction, but some occluded by more powerful claims of what can and should be prioritized, for who, for what purpose and by what means. We argue that understanding how these sets of ideas - conveyed through verbal discussion, the written word and visual images - develop and become materialized in policies, practices and physical forms is fundamentally important because they play a critical role in shaping recovery outcomes for different social groups (Fernandez and Ahmed, 2019, Sou 2019). We refer to the articulation of these sets of ideas, and their portrayal of events and people, needs and actions, as 'representations'. The diverse actors involved in recovery processes, including disaster-affected people themselves, as well as governmental and non-governmental organizations, and media commentators, consciously or subconsciously convey different interests and priorities via the representations they produce and share (Bornstein et al., 2013).

In the discussion that follows, we synthesize insights from the relatively limited body of research that exists on representational aspects of disaster recovery to explore further how dominant ways of thinking, and challenges to these, influence the support disaster-affected people receive, their capacities to recover, and their rights and agency in these processes. We also examine disaster-affected people's access to public memorialization, by which we mean their capacity to shape the ways in which the past is formally interpreted, and the extent to which their experiences of events are recognised or suppressed in official representations of the past. We draw on work from a range of countries, but with a particular focus on lowerincome contexts in India, where exposure to multiple hazards combines with deep-seated structures of social vulnerability. The first section outlines a little further the rationale for focussing on disaster recovery and what we mean by the role and relevance of representation. The next two sections describe how often-contested conceptions about the priorities for recovery action and the roles and needs of different actors in the recovery process tend to be constructed. We then focus on the generation and contestation of ideas about memorialization and commemoration, as key cultural and psychosocial dimensions of recovery. In the last two 
sections we turn to the means and possibilities for self-representation exercised by disasteraffected people themselves, and explore the potential for arts-based approaches to strengthen these mechanisms.

\section{Why focus on recovery, why focus on representation?}

Recovery from disaster events is a highly unequal process shaped by social, political, cultural and economic structures that frame the capacities of affected people and the external support that they receive over a sustained period (Zhang 2016; Anderson and Woodrow, 2019). Several decades of critical research on disaster risk have amply demonstrated that vulnerability to disaster impacts is conditioned as much by social factors as it is by the nature of the physical hazards that trigger the destructive events (e.g. Hewitt 1983; Cutter, 1996; Wisner et al., 2004). As such, vulnerability is inherently socially differentiated. But it is also crucial to recognize that these inequities are attenuated in time. Indeed, they can become magnified in the transition from emergency response to long-term recovery, as people try to rebuild their livelihoods in the aftermath of deeply disruptive shocks to society (Chhotray and Few, 2012; Hicks and Few, 2015; Jain et al., 2017).

That recovery is a complex and persistent challenge is revealed in many decades of attempts to learn from disaster events and build resilient pathways of recovery that reduce long-term impacts, enable transition out of chronic situations of risk, and promote sustainable and equitable development. Gains have been made, but global reports continue to discuss the scale, depth and continuity of recovery problems that hit hardest not only those with the fewest assets but those who have experienced profound personal and communal trauma (e.g. WHO, 2013; Hallegate et al., 2017; UNDRR, 2019). Research on long-term recovery and intervention has a key role to play in addressing the challenge (Davis and Alexander, 2016). This includes greater analysis of the social, cultural and political dimensions of recovery processes, and especially how they play out for poorer or more marginalized social groups across the world (Tierney and Oliver-Smith, 2012; Kammerbauer and Wamsler, 2017; Sovacool et al., 2018; Sou, 2019).

Key in this is recognising the importance of analysing how recovery needs and actions are represented and communicated by different actors (those directly affected by extreme events and those reporting on, discussing, supporting and making decisions about recovery actions), uncovering the forms, modes and motives of these representations (Bornstein et al., 2013). The concept of representation is associated with the ways in which actors and institutions, including the media, provide cultural resources that generate and reinforce shared public understandings of particular groups, events, experiences and phenomena. Systems of representation, through use of particular narratives, vocabularies and, also, silences, function to produce collective understandings of the world (Daya, 2019). The frames that the media construct around a news item, for example, provide 'interpretive storylines that set a specific train of thought in motion, communicating why an issue might be a problem, who or what might be responsible for it, and what should be done about it' (Nisbet, 2010, p15). Such narrative processes, generated and promulgated by influential actors, shape 'common-sense' views of people, events and issues, and legitimize policies and practices in all aspects of risk management and development (see e.g. Bebbington and Bebbington, 2012; Luig, 2012; Tebboth, 2013; Scott, 2014).

Representations of a disaster event, the people affected, and the appropriate priorities and approaches for action, we suggest, all ultimately shape recovery outcomes. Following a disaster, accounts, discussions, statements, and impressions of the unfolding situation produced and reproduced by individuals, organisations, and the media shape public opinion and influence decisions taken, actions followed, and how the event is (or is not) commemorated (Simpson and de Alwis, 2008; Chandrasekhar, 2010; Berlemann and Thomas, 2019). They become elements of a collective imaginary, and some will cohere with 
power relations in such a way that they become discursively inscribed in policies and practices of reconstruction, livelihood rehabilitation and memorialization.

The reach of different representations is itself unequal, and their construction and reproduction inevitably reflect underlying ideologies, interests, compulsions, and agendas (Cretney, 2017). These representational issues come especially to the fore in the post-disaster period, we suggest, because recovery support implies a long-term commitment: one that is more likely to be derailed by social, cultural and political division than actions taken during the immediacy of the event. However, ideas about recovery often can be traced to portrayals of need generated in the flush of emergency response. In the initial rush to respond to disaster events, for example, the rights and voices of affected populations tend to be interpreted by external actors in ways that homogenize and speak for them; affected people are rarely consulted or heard at such moments (Chandrasekhar 2010; Kruks-Wisner, 2011). Of course, it may often be practically and ethically difficult to consult disaster-affected people fully during the height of emergency operations such as rescue and evacuation, but this only makes it all the more important to continue giving effective voice to people as the period after an extreme hazard ensues. Instead, externally generated ways of thinking about the disaster event, and about affected people's needs and collective priorities, may come to dominate the public discourse (Gamburd, 2013). Longer-term responses to disaster events then have a tendency to approach the recovery process through technocratic and managerial fixes, downplaying more human-focused aspects and ignoring the individual and socially differentiated ways in which disaster, recovery and memories of the event are experienced (Andrew and Arlikatti, 2014).

However, though such 'mainstream' representations, produced and conveyed by institutions with greater material and political resources, may seem to dominate discussion, they are not monolithically accepted or believed in, but are defended, challenged and rejected by various actors (Lindahl, 2012; Jain et al., 2017). They constitute sites of contestation from which economic and political powers can be challenged and different ethical practices, norms and methodologies proposed and defended (Lin and McSweeney, 2010; Garden, 2015; Cretney, 2017). We contend therefore that the representational aspects of recovery play an important but relatively under-researched role in shaping recovery outcomes, in ways that we explore in the sections of the review that follow. First, we focus on the often-contested way in which priorities for recovery in the aftermath of disasters become constructed within society. Typically, these are biased toward certain forms and sectors of intervention by the representations of responsibility, need and value generated by more powerful agencies, including governmental and, in some cases, non-governmental organizations.

\section{Representing recovery: priorities and interventions}

Post-disaster periods are times of intense encounter between diverse social actors that have differing perspectives on priorities, underwritten by different capacities, resources and power (Chandrasekhar et al., 2014). Recovery, as a 'process' is composed of multiple actions that are performed by multiple actors, and most fundamentally by disaster-affected people themselves. Yet it often becomes articulated in terms of support provided through external 'interventions' (policies, programmes and projects) of national and international agencies. The way in which a disaster situation is represented determines how such agencies respond. At moments of crisis, governments tend to simplify complex, uncertain and contentious realities, making them fit their administrative needs (Bornstein et al., 2013). This act of 'typification, homogenization and standardization' (ibid, pp 45) is then transmitted into institutional and regulatory procedures in the form of codes, standards, and laws. These practices take place within contexts where power is not evenly distributed between the affected communities, the state, international and other private agencies, and may advance particular political and economic agendas (Comfort et al., 1999; Jain et al., 2017). Moreover, by presenting the event 
itself as a 'natural' disaster and praising the 'resilience' of those who face it, the focus is often shifted away from institutional and governance shortfalls, and instead depicts the disaster as unforeseeable hardship and therefore not an event that could have been prepared for or the response better managed (Ray-Bennett, 2009; Sou, 2019).

Critically, representation of disaster events, impacts and recovery needs mediates the processes through which recovery interventions become prioritized The recovery process that follows disasters should help people make sense of events and transform affected places, but interventions often proceed in ways that under-emphasize certain issues and may give rise to new social needs (Schwab, 2014). Furthermore, these circumstances create conditions through which communities can be excluded and differences exacerbated (Chandrasekhar et al., 2014). This may occur because of certain groups not being consulted or because of differing value systems. For example, examining recovery process after the 2004 Indian Ocean tsunami in Tamil Nadu, Raju (2013) found that relocation as the main instrument of recovery revealed deep divisions in priorities and conceptions of future 'risk' between disasteraffected citizens and the state. Fishing folk spoke of 'belongingness to the sea', loss of their space and customary livelihood rights over the coast, while the government rationalized relocation as motivated by safeguarding infrastructure and preventing further loss of lives. Bradshaw (2002) underlines how optimistic official narratives of recovery progress can often obscure underlying trade-offs in interventions as well as entrench unequal gender relations.

Nationally through governmental priorities, and internationally, through the priorities of aid organizations such as the World Bank's GFDRR, a major sectoral focus tends to be on housing, reconstruction and economic rehabilitation. Beyond the loss of life, disaster events bring attention to pre-existing infrastructural and economic vulnerabilities and are increasingly seen as an opportunity to 'build back better' to reduce future risk (Lyons, 2009; Hallegate et al. 2017), as endorsed in the global agreement, the Sendai Framework for Disaster Risk Reduction 2015-2030 (UNISDR, 2015). It is important to emphasize that, contrary to how it is sometimes interpreted, the overall concept behind this term is much wider than its label might suggest, covering also social, psychological, environmental and governance dimensions of disaster risk recovery and management (Wilkinson et al., 2018). Though housing, infrastructure and a return to economic productivity still tend to be emphasized in governmental priorities for post-disaster intervention (in part because such gains are more visible or measurable), recovery as a societal process therefore has significantly wider elements (Davis and Alexander, 2016). We examine in more detail the contested representations surrounding housing assistance in the accompanying Box (Re-housing disaster-affected populations in India), but, an example of another sector, one that has historically been neglected in national recovery priorities, is psychosocial support.

Psychosocial interventions in both the short and the long term are key for disaster recovery (Ruaida Abbas and Sulman, 2016; Zerrudo, 2016), and Chin and Talpelli (2015) argue that we need to broaden our understanding of community-level trauma and healing as social events. For Mooney et al. (2011), psychosocial recovery is an integral core that interconnects with all other dimensions of recovery. Yet, in many countries, the effects of disasters on the most vulnerable are often compounded by the poor provision of mental health support services (Kayser et al., 2008; Hechanova and Waelde, 2017). For example, Moniruzzaman (2010) showed how the inability of the Thai government to provide long-term mental health care for people at risk or in need of mental health support and services undermined affectedpopulations' ability to recover from the Indian Ocean Tsunami. That huge-scale disaster has since helped to trigger more focus on disaster mental health support, especially by international agencies, yet long-term investment in psychosocial recovery remains low.

However, if such interventions are to effect positive change, they need to be sensitive to local cultural coping preferences (Hechanova and Waelde, 2017). Chang (2005), for example, notes that individualistic western concepts of psychotherapy may alienate or re-traumatize 
disaster-affected people in contexts where trauma is experienced collectively. One vehicle through which a more pluralistic representation of psychosocial support needs can be explored is through incorporation of the creative arts. Though further critical research is needed, evidence to date on arts-based therapeutic approaches following disasters suggests that facilitating creative expression has potential to help heal trauma in ways that are ethically and culturally sensitive (Finley, 2007; Adnams Jones, 2018).

We return to these themes of psychosocial recovery and arts-based representation later in the paper. The next section focuses on the construction of ideas about actors themselves, on their roles, needs and capacities in the recovery process.

\section{The characterization of actors: power and agenda}

In addition to how disaster events, impacts and recovery processes become represented, it is also pertinent to understand how the roles of the different actors involved come to be portrayed, both by themselves and by others. The key characters on this stage are government authorities, national and international non-governmental agencies, local institutions and the disaster-affected people themselves, with the media intervening to provide (selective) exposure and commentary.

For the state, disasters accentuate the responsibility to provide protection and assistance. In many cases, the state presents itself from a moral position as caretaker or 'benevolent giver' to the needy (Jain, 2016; Jain et al., 2017; Le Mentec and Zhang, 2017; Courtney, 2018). Research following disasters in China has especially highlighted these characterizations, though they are constructed roles likely to be replicated at least in part across many different political regimes. Analyzing print and television news reports, Xu (2016, p410) describes attempts by the Chinese government to 'project an image of a secure, heroic state' postdisaster, one that constructs a 'sympathetic image through leaders' display of compassion and sorrow', in an effort to 'repair its image amid crisis'. In doing so, the state seeks consent and cooperation from wider audiences, but also often seeks to reinforce its power among disasteraffected citizens through cementing their gratitude for the assistance received (Zhang, 2016; Le Mentec and Zhang, 2017). Similarly, though they are instituted with a clear purpose and mandate, humanitarian aid organizations act in the context of multiple, sometimes competing motivations. The agendas and priorities that they construct evolve and adapt, underpinned by normative concerns, but shaped also by internal interests and the need to maintain external relations and image (Paulmann, 2013; Maxwell and Walker, 2014).

Disaster intervention and disaster aid confers power on the giver to decide and shape forms of post-disaster development. Portrayals of affected communities and the inherent biases within them (e.g. deserving versus undeserving aid recipients) may reinforce hegemonic/economic relations and discursively create certain channels for intervention prioritized by the donor (Zhang, 2016). Similarly, Drake (2016) finds that governmental bodies set up to manage the impacts of disaster may represent poorer disaster-affected populations in a blanket way as uninformed and manipulated by activists, despite an evident diversity of viewpoints on the ground. Plans of actions based on such 'constrained understandings of victims and their needs', argues Drake (2016, p360), will inevitably underperform.

A further layer of representational power lies within local institutions that intervene formally and informally in shaping the political economy and social norms of recovery processes. Religious leaders and faith-based groups, for example, play a critical role in recovery processes in tangible ways through material support, as key nodes in information networks, and intangibly by providing explanation, solace and space for grieving, and memorialization (McGeehan and Baker, 2017). Religious leaders often have contextual information about impacts and hold high levels of trust among disaster-affected populations, thereby acting as 
key mediators of representation in the recovery process (Stern, 2007; Ramirez and Taylor, 2013; Bhattacharjee, 2019). Yet, local institutional actors may also pursue often hidden agendas at such times of crisis, utilising channels of recovery assistance to which they have access to strengthen systems of patronage. Bhattacharjee (2016), for example, points to a 'strategy of social welfare' used by religious political agents in India during post-disaster periods to 'facilitate the creation of a humanitarian image' for itself and thereby build political support over time.

In contrast, people directly affected by disasters tend to have limited access to mainstream platforms through which to voice their needs. The experiences of women, of racial and ethnic minorities, and of the poor in trying to claim their rights reveal still greater marginalization, though such groups often navigate different channels to pursue their agendas (Kruks-Wisner, 2011). Commonly, mainstream media practices reinforce these patterns. Discussing the aftermath of the Union Carbide industrial disaster in Bhopal, Sharma (2014, p158) indicated how survivors' roles in media reports tended to be limited to providing 'emotional and reactive soundbites', while interviews and discussions about support processes centred on the technical authority of experts. The prevalence of certain narratives of 'victimhood' can actually eclipse pre-disaster social conditions and relations that could otherwise be mobilized to strengthen recovery. For example, Santha $(2018$, p75) argues that in fishing communities in Tamil Nadu after the 2004 tsunami, 'victims' were predominantly represented externally as 'completely dependent people in need of relief and rehabilitation', and this interpretation curtailed attempts to 'identify and use existing local capabilities and resources for recovery'.

Dominant print and broadcast media representations of post-disaster processes can not only perpetuate existing socio-spatial inequalities but may also create new patterns of marginalization and exclusion (Chandrasekhar et al., 2014; Jain et al, 2017; Sou, 2017). In some situations, historical, cultural and racial stereotypes are mobilized to justify the authority of the state in undertaking post-disaster interventions (Bornstein et al., 2013). Again, the media often repeat and reinforce such representations. Tierney et al. (2006) suggest that, despite evidence that affected people do not passively await outside aid but proactively assist one other, the media may normalize images of chaos, looting, panic and criminality to represent affected areas as war zones. Such representations can justify the militarization of state responses. Lindahl (2012) shows how in the aftermath of 2005 Hurricane Katrina, media accounts represented poorer New Orleans residents as criminals, in communities too disordered and chaotic to be helped. The contrasting narratives of survivors, that tended to attach guilt to government agencies perceived as not ordered enough to engage with them, were routinely rejected by the mainstream media.

\section{[BOX] \\ Example of contested representation: Re-housing disaster-affected populations in India}

In order to illustrate the contested, or contestable, way in which mainstream representations of recovery emerge, we delve here in more detail on the issue of housing assistance following disaster events in India. As noted, resettlement and reconstruction are key interventions in the disaster recovery process, ideally creating the conditions necessary to overcome infrastructural impacts of disasters, help people live safer lives, and 'build back better' (Bornstein et al., 2013; Fernandez and Ahmed, 2019). In the aftermath of disasters, resettlement and reconstruction are often represented by government as priorities in order to reduce hazard exposure. In political terms, housing provision is also a 'tangible', physical intervention, one that renders government support visible to citizens in a way that psychological support or capacity building may not. However, the literature indicates that the manner in which ideas around rehousing are constructed tends to obscure socio-economic vulnerabilities linked to local livelihoods, place attachment and the psychosocial impacts of 
relocating, as well as homogenize differentiated needs and hopes (Raju, 2013; Andrew and Arlikatti, 2014; Jain et al., 2017).

Two broad themes around issues of representation and inclusiveness are foregrounded when dealing with housing - either through resettlement or reconstruction. First is the issue of who is deemed 'worthy' of receiving houses, with 'beneficiary' identification processes leading to inclusion and exclusion and often deepening pre-existing inequities (Jain, 2016). For example, examining reconstruction after the 2001 Bhuj Earthquake in Gujarat, Mukherji (2018) found that the government mainly targeted the needs of those who legally owned property. This meant that the most marginalized - squatter households or those who were not homeowners - were excluded from recovery processes. Second is the idea of what constitutes acceptable rehousing. Even when disaster-affected people are given housing, resettlement processes often move them far from where they live, and in some cases this means long hours of commuting for work, loss of sense of self and identity, and unsafe living conditions (Raju, 2013; Andrew and Arlikatti, 2014; Jain et al., 2017).

Over time, resettlement interventions demonstrate different conceptions of inclusion in postdisaster recovery processes, and often highlight an erosion of agency in post-event, traumatic situations. Examining relocation after the 2004 Tsunami and 2015 Chennai floods, Jain et al. (2017) note how people reported a lack of autonomy in deciding when and where they were moved. This resulted in confusion and distrust (between those relocated and the State), hesitation (given the lack of information about available choices), and resistance (to move, and later, to accept the new houses). Housing interventions also highlight a clash of values between those affected by disaster and those implementing resettlement and reconstruction activities. For example, across India, post-disaster housing has faced issues of not being sensitive to local customs, needs, and livelihoods, such as not using indigenous construction technologies, or dividing communities across housing blocks (Raju, 2013; Andrew and Arlikatti, 2014).

However, reconstruction need not always erode agency. As Shinde (2017, p. 396) notes, during post-flood reconstruction in Pune, the government model of Cooperative Housing Societies added 'a new layer of heritage' to the city, tangibly through new housing, and intangibly through building community resilience to trauma. Community participation and coproduction (of interventions and solutions) has been identified as key to effective and inclusive housing-based recovery (Thomas et al., 2011; Andrew and Arlikatti, 2014). Based on experiences after the Gujarat earthquake in 2001, Thomas et al. (2011, p. 752) note that coproduction in rehabilitation and reconstruction allowed for 'psychological acceptance of people's own abilities and enabled them to return to a changed state of life after a traumatic event'. While questions remain in defining processes of co-production and how it is supported, this movement demonstrates the central role that affected populations can play in being given opportunities to represent their own needs in relocation and reconstruction processes.

\section{The contested roles and practices of memorialization}

In many societies, memorialization is a key facet of individual and collective recovery from disasters (Zavar and Schumann, 2019). Memorialization takes many forms as something that can be material, ceremonial or abstract, but essentially it constitutes a device to help people think about, make sense of and, sometimes, learn from an event (Simpson and de Alwis, 2008; Cassim, 2013). It emerges as folk tales and stories, as shared experiences ritualized in religious fora, as official commemorations, and as physical, symbolic memorials constructed in sites of disasters. Memorialization can also be a very private affair, in which events, losses, and trauma can be signified, captured through 'embraced artefacts' such as photograph albums and the walls of a house, and acknowledged through funerary and calendrical rites (Simpson and Corbridge, 2006). 
Memorializations are inherently representational. Physical memorials, for example, serve to signal what is deemed important for those who design and establish them. After the Bhuj earthquake in Gujarat, memorials were tied to the politics of religious communalism, regionalism, and mainstream Hindu nationalism, while in Sri Lanka, tsunami memorials were local manifestations of ethno-nationalisms and state hegemony (Simpson and de Alwis, 2008). These state-led memorials meant that non-Hindu and non-Sinhala losses were seemingly erased, obscuring religious and ethnic plurality. In post-disaster sites where there are preexisting religious differences, these can be reflected in disagreements about the content, meaning and symbolism of memorials and commemorations (Eyre, 2007). These conflicts highlight the importance of questioning who is representing what and whom.

Official memorialization and commemorative practices also have political value. Generally, they are designed to represent events, heroes and victims in ways that are defined by the state, often to homogenize and formalize the collective memory of a disaster and use that memory for present and future state purposes (Eyre, 2007; Colten and Giancarlo, 2011). Official memorialization is politicized in ways that can deny the agency of those affected and perpetuate disempowerment. Le Mentec and Zhang (2017) provide a stark illustration of these processes through their analysis of 'heritagisation' programmes undertaken by the Chinese government after the 2008 Wenchuan earthquake. Some devastated urban landscapes became preserved as relics, while others were reconstructed as heritage tourism destinations. These actions were seen as imposed from above, insensitive to the affected people's trauma, alien to the socio-historical context, and thereby out of step with their stated objective of promoting 'cultural recovery' (Le Mentec and Zhang, 2017, p350).

State commemorations of anniversaries of tragedies are similarly highly political events intended to represent the passage toward rehabilitation and recovery. These official representations can anger and re-traumatize survivors, who may boycott such commemorations to protest against political uses of the disaster event (Eyre, 2007). The official memorialization and commemoration of disasters can also, perversely, erode social memory and lead to loss of resilience (Colten and Giancarlo, 2011). Baez Ullberg (2018) found that memorialization and commemoration of a flood disaster in Argentina in 2003 reduced embedded local memories of recurrent flooding and thus reproduced risk for future flooding. Similarly, Logan (2015) argued that state-sponsored bushfire commemoration activities in Victoria, Australia, may help societies remember pain and suffering, but can 'divert attention' from more fundamental questions about what can be done to ensure the same catastrophe does not happen again. These examples highlight the need to 'protect and sustain' social memory in order to integrate local knowledge of disaster events into memorialization processes (Colten and Giancarlo, 2011).

At a grassroots level, a diversity of voices may also compete for recognition in post-disaster memorialization (Alderman and Ward, 2008). For example, following the Piper Alpha North Sea disaster of 1988, its commemoration was fought over not only by oil companies and families, but also between families, who disagreed on how, where and for what reasons the event should be commemorated (O'Byrne, 2011). Memorials represent and interpret disaster experiences, but while studies highlight the need to involve communities in the establishment of permanent memorials (Eyre, 2007; Zavar and Schumann, 2019), the question remains of how different voices and opinions in the community can be effectively brought together.

\section{Self-representation: disaster-affected peoples' voice and agency in recovery}

As has become clear, disaster-affected people are not passive recipients of external representations. Individually and communally, they generate their own framings of the situation, and in some cases they are able to actively renegotiate and transform externally- 
imposed representations about themselves and their needs. Indeed, Chandresekhar et al. (2014, p373) indicate that disaster situations can sometimes offer new opportunities for people, creating conditions that can 'rebalance power relationships and create more opportunities for participation by marginalized groups.'

But seizing this opportunity may not just be a matter of 'finding' voice, but actually of reshaping voice and agency in the sense of reconfiguring self-representation (of individuals, or of the groups that individuals seek to represent). Zhang (2016), while emphasizing the power of aid agencies to shape recovery priorities, records cases where disaster-affected people actively used that intervention environment to reform their identities in order to press for action. Drawing on Barrios (2014), Zhang also cites the example of uncustomarily-assertive grassroots movements forming in Honduras after Hurricane Mitch (1998), when the depth of the post-disaster crisis strengthened their hand in resisting and overturning entrenched patterns of clientelism in housing relocation projects.

At times, actors have therefore been able to positively influence outcomes by 'stepping outside their normal boundaries' (Chandrasekhar et al., 2014, p380). These cases highlight how the initial activities in the early-recovery or response phase tend to bleed into the longer-term recovery period. The disruption of typical path-dependent decision-making processes in development and planning following disaster events creates conditions that groups normally marginalized from decision-making are able to utilize to influence recovery outcomes. Similarly, Kruks-Wisner (2011) presents evidence to show that the 2004 tsunami created a window in which 'groups came to "see" and interact differently with the state', although it is important to recognize that these interactions were strongly mediated by pre-existing structural conditions and social identities such as gender and caste. Ray-Bennett (2006, p249) sees disaster situations acting as catalysts by simultaneously 'breaking down cultural barriers and solidifying them', both these effects shaping agency and control over recovery priorities and processes.

A number of authors emphasize that a strong sense of community, a communal identity, and shared accounts of impact and trauma play a critical role in recovery (Chin and Talpelli, 2015; Richardson and Maninger, 2016; Misra et al., 2017). Construction of a communal coping narrative for reciprocal patterns of emotional expression and shared problem recognition (Kayser et al., 2008). Additionally, social networks and communal coping practices shape the flow of post-disaster support in the form of information, material, and services offered to the affected communities as seen after the 2004 tsunami in Tamil Nadu (Misra et al., 2017) and Hurricane Ike in USA in 2008 (Richardson and Maninger, 2016). Social ties and networks therefore mediate post-disaster recovery experiences by shaping who and what is represented, and who holds agency over this representation. These social networks span various forms of support from kinship-based ties such as family-based support systems (Perera-Mubarak, 2013), to community-based collectives of affected people (Richardson and Maninger, 2016) and ad hoc networks of concerned actors, often coming together in postdisaster situations (e.g. citizen groups after Chennai floods) (Jain et al., 2017; Joerin et al., 2018). In some cases, disasters allow new networks to form, as Chandrasekhar et al. (2014) show through the formation of Dalit and women-only networks after the 2004 tsunami, overcoming historical inequalities and facilitating traditionally marginalized stakeholders to gain access to formal decision-making processes over time.

Nevertheless, it is important also to retain a critical perspective on the construction of ideas at the grassroots, and recognize that shared representations of disaster and agency can negatively, as well as positively, shape recovery (Ray-Bennett, 2006; Bornstein et al., 2013; Arunatilake, 2018; Daly, 2018). Social identities, whether based on gender, ethnicity, caste, religion or other axes, filter the experience of disaster impact and recovery. Religious beliefs, for example, play an important role in mediating how disaster events are interpreted and represented (McGeehan and Baker, 2017). Even among non-practising individuals in 
traditionally secular societies, religious rituals and attendance at religious sites increases in the immediate aftermath of a collective tragedy (Eyre, 2007). Such situations of extreme shock and trauma can lead people to turn to religion to make sense of their grief and losses, often looking to answer questions of mortality and cause (Hoffman and Oliver-Smith, 1999; Schipper, 2010; Cannon, 2015). Gergan (2017) described how communities affected by earthquake in the Darjeeling Himalayas rationalized the disaster and its losses by suggesting it was because they had sinned and were being reprimanded by the local deities. Such representations of disasters as being the result of a 'transgression of moral codes' can on one hand be central to communities' social and cultural heritage, but can also undermine recovery processes when these beliefs and practices 'circumvent arguments about causes of risk and approaches to its reduction' (Schipper, 2010, p377).

Moreover, marginalized communities or those without access to social networks and ties often find themselves excluded from formal or informal networks, or their concerns misconstrued. Firstly, in post-disaster situations, social network representatives tend to speak on behalf of their members, and this representation by proxy can mask community heterogeneity and determine whose voice gets heard. For example, Perera-Mubarak (2013, p.671) highlights that after the 2004 tsunami in Sri Lanka women were typically portrayed as undifferentiated, agentless victims, despite some being critical nodes in kin networks where they leveraged 'relationships and associated social capital for economic and non-economic gains posttsunami'.

Secondly, the needs of certain marginalized groups may not be recognized at all through social networks. For example, in Tamil Nadu, tsunami relief tended to flow through local governance institutions which often focussed on their connections to fishing communities and excluded marginalized non-fishing groups such as Dalits, exacerbating intra-community differences and vulnerabilities (Chandrasekhar et al., 2014; Kushwaha, 2018). This highlights the danger of existing social networks and institutions reinforcing socially embedded inequalities and operating along uneven power hierarchies (Bornstein et al., 2013). It also reveals how a homogeneous representation of 'community' (Titz et al., 2018) can obscure historical lineages of vulnerability and exclusion, and undermine longer-term recovery.

But there are indications that representational barriers operating within communities and social groups can also break down in the crucible of post-disaster power dynamics. Empirical evidence amply shows that women often take on the key role in accessing relief and aid, performing critical caregiving duties including trauma care, and enabling financial recovery through re-engaging in livelihoods (Kayser et al., 2008; Kruks-Wisner, 2011; Perera-Mubarak, 2013). There is increasing recognition that such post-disaster situations can provide an entry point to reconfigure ideas about gender norms and family structures (Ray-Bennett, 2006; Perera-Mubarak, 2013), enabling the voicing of divergent opinions and more strident articulation of women's needs. Kruks-Wisner's (2011) description of elderly women learning their rights and demanding pensions after the 2004 tsunami underlines the need for an intersectional understanding of identity in analysing the dynamics of representation.

\section{The (neglected) role of the arts in recovery processes}

Lastly, reflecting increasing interest in arts-based approaches to development (Ware and Dunphy, 2020), we consider the role that creative arts may play in opening channels for selfexpression and facilitating disaster-affected people's recovery. Emerging evidence suggests that arts-based programmes have potential to widen processes of participation, and open spaces for marginalized people to articulate their needs, concerns and strengths (Ebersöhn and Malan-Van Rooyen, 2018). Huss et al (2016) used a creative project (building collages from natural materials) to evaluate how Sri Lankan people affected by flooding viewed the arts within disaster relief programmes. They concluded that the arts provide a culturally appropriate 
medium that enables disaster-affected people and community workers to communicate effectively and participate in problem-solving and can therefore play an important role in the recovery process. This is a field that would therefore greatly benefit from further critical analysis.

Several authors already advocate the use of arts in psychosocial support. Linton (2017) discussed how art therapy, using resources from the natural environment, allowed earthquake-affected people in Nepal to build connections and collaborate with support agencies, despite scarce resources. Working in Haiti, Puleo (2014) found that the visual arts, which he referred to as 'humanistic activities', allowed people traumatized by earthquake to re-imagine and articulate their future connection with place. Miichi (2016) argued that folk performing arts troupes enabled coastal communities in Japan, after the 2011 earthquake, tsunami and nuclear disasters, to rebuild community, process loss and trauma, and memorialize the dead and bereaved. Chang (2005) showed how in Taiwan, where people tended to have little trust in psychotherapists or social workers, survivors of the 1999 earthquake were empowered and supported by community-based drama, theatre and arts activities. Zerrudo (2016) argued that, following disasters in Nepal and the Philippines, creative activities such as storytelling, music, theatre, games and visual arts were central to survivors' rehabilitation, their memorialization of the past, and their collective re-imagining of the future.

It is suggested that the arts can positively affect long-term psychological recovery. Mohr (2014) used photo elicitation and visual arts methods to study perceptions of post-traumatic growth, three years after the 2007 earthquake in the Ica region of Peru, amongst young members of a performing arts group who had experienced the disaster. She found that the arts interventions provided a means to engage communities and for participants to explore their feelings. While Mohr was careful not to assert a cause-effect relationship between the arts and post-traumatic healing, she found that her respondents drew on the arts to attribute meaning to their traumatic experiences. Further research is needed to understand the mechanisms by which arts interventions can shape recovery processes and support postdisaster wellbeing in different socio-cultural contexts (Bender et al, 2015). In comparing arts interventions and recovery outcomes in Talca, Chile (after the 2010 earthquake) and New Orleans (after the 2005 Hurricane Katrina), Bender et al $(2015$, p11) found 'essential differences' in community solutions and the ways in which the content of artworks 'linked to cultural and contextual narratives'. For example, while New Orleans residents approached artmaking as a means of personal self-expression and of depicting individual attributes related to their survival, in Talca participants preferred to collaborate in their art-making and depict their survival within the context of a shared journey in a collective environment. The authors contend that such differences highlight the importance of understanding local cultural norms and expectations around how recovery can be supported through creative expression.

Finally, it is important to underline that disaster-affected people by no means rely on outsiders to introduce arts-based opportunities for reflection and self-representation. Many will turn to such means of expression to make sense of their experience and convey their interpretations. Rivera-Santana (2020) argues that many Puerto Rican visual artists affected by the 2017 Hurricane María drew heavily on a form of 'decolonial aesthetics' in their subsequent art. She states that in work such as the Defend Puerto Rico project-collective's 2018 installation, 'Rebuild Comerío: Imagine a Puerto Rico Recovery Designed by Its Communities', artists sought to examine the colonial condition and show how it contributes to a hyper-vulnerability to hazards. Rivera-Santana contends that such visual art, displayed via exhibitions both in Puerto Rico and the USA, aimed to convey socio-political discontent, and was intended to act as a critique of the US government's delayed and insufficient relief response. Similarly, Kish (2009: 673) discusses how, in the wake of Hurricane Katrina, hip-hop became a 'critical site for interrogating the ongoing tragedy of African American bodies that don't matter' to the government. Kish (2009: 672) argues that, while dominant media and government representations constructed hurricane victims as 'outside the norms of middle class white 
citizenship - and indeed a threat to it', Black hip-hop artists, from New Orleans and elsewhere in the USA, created songs (such as Houston's The Legendary K.O. group's 'George Bush Doesn't care About Black People') that asserted survivors' voices and challenged media depictions of Black New Orleans residents as a long-term drain on the country's resources. She argues that such songs provided alternative frameworks for understanding the economic and racial marginalization of hurricane survivors as the result of structural inequalities. A key research challenge arising from contributions such as those of Kish and Rivera-Santana is to try to understand better if and how such uses of the arts have impacted on dominant representations in such a way that they significantly influenced recovery outcomes.

\section{Conclusion}

Recovery is not a neutral concept: it is political in nature, contested in its representation and differentiated in its outcomes. Actors possess competing visions of what disaster recovery looks like and competing ideas about the best way to achieve it. Like all representations of social issues, these conceptions and perspectives coalesce within society, produced and reproduced as shared frameworks of understanding that tend to reflect different social positions, roles and associated worldviews. Understanding how these representations evolve over time, and who they privilege or work against, are issues of central importance in managing the long-term consequences of disasters. Drawing on a diverse but relatively sparse field of literature on representational aspects of recovery, this discussion draws together existing insights on how, by whom and for what purposes processes and experiences of recovery tend to be framed in the post-disaster period. It also examines the differential agency of disaster-affected people to create their own representations in ways that may influence recovery and memorialization processes.

Critical analysis of recovery practices, especially those that take the form of programmatic interventions, reveal how these commonly reflect dominant representations of what recovery entails, or should entail, that both simplify the situation and negate alternative voices. In doing so, they have the potential to undermine recovery for those most vulnerable to long-term impacts, through a capture of priorities that neglects key needs and through an approach that excludes some groups from effective support. Governmental responses to disaster events have a tendency to view the recovery process through technocratic, infrastructure-centric, and managerial fixes, downplaying the more wellbeing-focused aspects (such as recovery from non-material losses) and the individual and socially differentiated ways in which disaster and recovery are experienced. Typically, actions by governmental actors and other organizations offering support to the affected communities operate through a political, interest-based logic, even if a genuinely humanitarian motive is operating alongside. Actions around the theme of memorialization illustrate this duality particularly well, with the construction of physical memorials and the staging of commemorative events often functioning more as tools of politics than as mechanisms for post-traumatic healing or for conserving social memory of disaster risk.

However, it is important to recognize also that dominant or mainstream representations of appropriate intervention themselves reflect underlying representations of the people undergoing recovery and of the disaster event that has affected them. For example, media portrayals of affected populations as agentless 'victims', reliant on relief handouts, trapped in place-attachment to hazardous locations and/or persisting with livelihood choices regarded as inherently at risk, may have a direct impact on the decisions made and interventions implemented by governmental and non-governmental agencies. Alternatively, the hardships experienced in recovery can become belittled by equally problematic portrayals of people as 'resilient' beings showing fortitude in the face of losses. Though all these constructions can be challenged, there can be an element of undeservedness implicit in how people meeting these conceptions are viewed, which might even be expressed through withdrawal or exclusion from services. On the other hand, portraying disaster-affected people as inherently 'resilient' can 
serve to absolve state actors from the long-term repercussions of inadequate or misaligned recovery interventions. Further, these representations of people are bound up in how the impacts of the event itself and resultant needs are portrayed. Officials collecting data on disaster impacts, for example, tend to record tangible impacts - loss of housing, damage to hard infrastructure such as roads and power supplies, and measurable economic indicators. Much less monitoring and reporting attention is given to intangible impacts such as trauma, loss of social networks, detachment from a secure sense of home, and loss of local cultural heritage. Partly as a consequence of this, psychosocial dimensions are often overlooked in representations of disaster affected people and their needs.

Though more critical research is needed to understand how dominant representations emerge and take hold, it is also key to understand better how these can be, and are being, contested and challenged, and help to move toward more informed, inclusive and supportive visions and processes of recovery. Disaster-affected populations do not passively accept adverse portrayals, but contest and challenge them, either directly through protest or indirectly through constructing forms of self-representation. Often, they do so through alternative channels such as community arts, local radio, public meetings, connections to advocacy groups, or their own personal interactions. Research work can play a key role in this, we argue, if it can increase understanding of how to enable fairer, more inclusive representation of the identities and priorities of marginalized groups within the recovery process. There is, for example, a shortage of research on how individual desires for memorialization can be acknowledged, respected and supported, and how official memorialization can bring voices of those affected into formal processes. We also highlight the potential role that arts-based approaches can play in fostering opportunities for people to take greater control of their own recovery experiences. We find little attention to the ways cultural expression may be interlinked with recovery: for example, studies of music and its relationship to political action tend to focus on social movements, but the use of hip-hop after Hurricane Katrina shows how songs can serve important functions that remain under-researched in the context of disaster recovery. Future research needs to critically investigate the consequences of these framings and suggest ways to bring the voices of the affected more centrally into societal representations of disasters.

There remain gaps in the literature around the role that more informal social networks such as citizen groups can play in representation and recovery. Commonly ad-hoc and self-appointed, such groups are often driven by concern but not necessarily expertise. They can also reflect specific interests. In heterogeneous communities even 'grassroots' portrayals of disaster impacts and needs can be exclusionary, with the most marginalized voices being drowned out by those with the strongest political ties or those with dominant platforms. One key field of enquiry related to this is the role of access to social media in self-representations of recovery, and the balance between its inclusionary and exclusionary effects. In contexts where there is highly differentiated access to digital technologies the use of social media may offer some the chance to voice personal perspectives on recovery, but, to others, it can remain a domain of exclusion (see e.g. Tewathia et al., 2020). Critical engagement is also needed to explore how the heterogeneity of community membership is reflected in access to external aid providers, and the contingent relations of how the notion of 'community' may be reconstructed in such situations.

Drawing these elements together, we underline the importance of linking representations of disaster events, of people affected (and their needs), and of processes (actions and interventions), and analysing how together they shape recovery trajectories for different social groups. We argue that a greater understanding of the ways in which patterns of representation structure how actors imagine and respond to the long-term impacts of disasters is necessary for more effective and inclusive support initiatives. No representation is inherently good or bad, but recognising the agendas they portray, and whose voice they intentionally or unintentionally silence is essential to the recovery of more marginalized social groups. Disasters create shared yet fundamentally differentiated experiences. Those whose needs and capacities 
remain poorly conveyed or are even misrepresented within mainstream framings of recovery have a greater likelihood of being excluded from effective recovery processes in the long-term, deepening pre-existing inequities and vulnerabilities.

\section{REFERENCES}

Adnams Jones S (2018). Art-Making with Refugees and Survivors: Creative and Transformative Responses to Trauma after Natural Disasters, War and Other Crises. Jessica Kingsley Publishers.

Alderman D and Ward H (2008) Writing on the plywood: Toward an analysis of hurricane graffiti. Coastal Management 35: 1-18.

Anderson MB and Woodrow PJ (2019) Rising from the Ashes: Development Strategies in Times of Disaster. Routledge.

Andrew SA and Arlikatti S (2014) Multi-sector partnerships in disaster housing recovery: An examination of housing development approaches in India. In: Kapucu N and Liou KT (eds) Disaster and Development. Springer Science \& Business Media, pp 351-369.

Arunatilake N (2018) Post-disaster housing: Lessons learnt from the 2004 Tsunami of Sri Lanka. In: Reddy S (ed) The Asian Tsunami and Post-Disaster Aid, Springer Singapore, pp211-232.

Baez Ullberg S (2018) Learning from loss? The politics of memory and morality in the postdisaster. RCC Perspectives 3: 79-84.

Bebbington DH and Bebbington A (2012) Post-what? Extractive industries, narratives of development, and socio-environmental disputes across the (ostensibly changing) Andean region. In: Haarstad $\mathrm{H}$ (ed) New political spaces in Latin American natural resource governance (pp. 17-37). New York: Palgrave Macmillan, pp17-37.

Bender B, Metzl E, Selman T, Gloger D and Moreno N (2015) Creative soups for the soul: Stories of community recovery in Talca, Chile, after the 2010 Earthquake. Psykhe 24(1): 1-13.

Berlemann $\mathrm{M}$ and Thomas $\mathrm{T}$ (2019) The distance bias in natural disaster reporting--empirical evidence for the United States. Applied Economics Letters, 26(12): 1026-1032.

Bhattacharjee M (2016) Seva, Hindutva, and the politics of post-earthquake relief and reconstruction in rural Kutch. Asian Ethnology, 75(1): 75-104.

Bhattacharjee M (2019). Disaster Relief and The RSS: Resurrecting 'Religion' Through Humanitarianism. Sage Publications.

Bornstein L, Lizarralde G, Gould KA and Davidson C (2013) Framing responses to postearthquake Haiti: How representations of disasters, reconstruction and human settlements shape resilience. International Journal of Disaster Resilience in the Built Environment 4(1): 43-57.

Bradshaw S (2002) Exploring the gender dimensions of reconstruction processes posthurricane Mitch. Journal of International Development 14(6): 871-879.

Cannon T (2015) Disasters, climate change and the significance of 'culture'. In: Krüger F, Bankoff G, Cannon T, Orlowski B and Schipper ELF (eds) Cultures and Disasters: Understanding Cultural Framings in Disaster Risk Reduction. New York: Routledge, pp88-106.

Cassim S (2013) Re-membering those lost: The role of materiality in narrative repair following a natural disaster (Masters Thesis, University of Waikato, New Zealand.

Chandrasekhar D (2010) Understanding stakeholder participation in post-disaster recovery (case study: Nagapattinam, India) (Phd Thesis, University of Illinois at UrbanaChampaign, USA).

Chandrasekhar D, Zhang $Y$ and Xiao $Y(2014)$ Nontraditional participation in disaster recovery planning: Cases from China, India, and the United States. Journal of the American Planning Association 80(4): 373-384.

Chang I (2005) Theatre as therapy, therapy as theatre: Transforming the memories and trauma of the 21 September 1999 earthquake in Taiwan. Research in Drama Education 10(3): 285-301. 
Chhotray V and Few R (2012) Post-disaster recovery and ongoing vulnerability: Ten years after the super-cyclone of 1999 in Orissa, India. Global Environmental Change 22(3), 695-702.

Chin NP and Talpelli M (2015) "You always have to struggle, so you don't have to struggle": Community trauma recovery after a landslide. Journal of Loss and Trauma 20: 306316.

Colten CE and Giancarlo A (2011) Losing resilience on the Gulf Coast: hurricanes and social memory. Environment: Science and Policy for Sustainable Development 53(4): 6-19.

Comfort L, Wisner B, Cutter S, Pulwarty R, Hewit, K, Oliver-Smith A et al. (1999) Reframing disaster policy: the global evolution of vulnerable communities. Global Environmental Change Part B: Environmental Hazards 1(1): 39-44.

Courtney C (2018) At war with water: The Maoist state and the 1954 Yangzi floods. Modern Asian Studies 52(6): 1807-1836.

Cretney RM (2017) Towards a critical geography of disaster recovery politics: Perspectives on crisis and hope. Geography compass 11(1): e12302.

Cutter SL (1996) Vulnerability to environmental hazards. Progress in Human Geography 20: 529-539.

Daly P (2018) An applied anthropological perspective on localizing post-disaster aid: Lessons from post-tsunami Aceh, Indonesia. In: Reddy S (ed) The Asian Tsunami and Post-Disaster Aid, Springer Singapore, pp101-119.

Davis I and Alexander D (2016) Recovery from Disaster. London and New York: Routledge.

Daya S (2019) Words and worlds: Textual representation and new materialism. Cultural Geographies 26(3): 361-377

Drake P (2016) Multiple visions of Indonesia's mud volcano: Understanding representations of disaster across discursive settings. Disasters 40(2): 346-364.

Ebersöhn L and Malan-Van Rooyen M (2018) Making the most of culture and context: sociocultural strengths and contextual vulnerability when eliciting indigenous resilience insights with remote South African elders and young people. International Journal of Qualitative Methods 17: 1-21.

Fernandez G and Ahmed I (2019): "Build back better" approach to disaster recovery: Research trends since 2006. Progress in Disaster Science, 1, 100003.

Finley S (2007) Arts-based Research. In Knowles JG and Cole AL (eds) Handbook of the Arts in Qualitative Research, Sage Publications, pp. 71-81.

Gamburd MR (2013) The Golden Wave: Culture and Politics after Sri Lanka's Tsunami Disaster. Indiana University Press.

Garden R (2015) Who speaks for whom? Health humanities and the ethics of representation. Medical Humanities, 41:77-80.

Gergan MD (2017) Living with earthquakes and angry deities at the Himalayan borderlands. Annals of the American Association of Geographers 107: 490-498.

Hallegate S, Rentschler J and Wals B (2017) Build Back Better: Achieving Resilience Through Stronger, Faster, and More Inclusive Post-Disaster Reconstruction. World Bank, Washington.

Hechanova R and Waelde $L$ (2017) The influence of culture on disaster mental health and psychosocial support interventions in Southeast Asia. Mental Health, Religion \& Culture, 20: $31-44$.

Hewitt K (ed) (1983) Interpretations of Calamity: From the Viewpoint of Human Ecology. Winchester: Allen \& Unwin.

Hicks A and Few R (2015) Trajectories of social vulnerability during the Soufriere Hills volcanic crisis. Journal of Applied Volcanology 4 (10).

Hoffman SM and Oliver-Smith A (1999) Anthropology and the angry earth: An overview. In: Oliver-Smith A and Hoffman SM The Angry Earth: Disaster in Anthropological Perspective, Routledge, pp1-16.

Huss E, Kaufman R, Avgar A and Shuker E (2016) Arts as a vehicle for community building and post-disaster development. Disasters 40(2): 284-303.

Jain G (2016) Risk-related resettlement and relocation in urban areas: Research framework 
and summary of findings, Indian Institute for Human Settlements (IIHS), Bangalore, India. https://doi.org/10.24943/cirf1.2016

Jain G, Singh C, Coelho K and Malladi T (2017) Long-term implications of humanitarian responses: The case of Chennai, International Institute for Development (IIED), London, UK. http://pubs.iied.org/10840IIED/

Joerin J, Steinberger F, Krishnamurthy RR and Scolobig A (2018). Disaster recovery processes: Analysing the interplay between communities and authorities in Chennai, India. Procedia Engineering 212: 643-650.

Kammerbauer M and Wamsler C (2017) Social inequality and marginalization in postdisaster recovery: Challenging the consensus. International Journal of Disaster Risk Reduction 24: 411-418.

Kayser K, Wind L and Shankar RA (2008) Disaster relief within a collectivistic context: Supporting resilience after the tsunami in South India. Journal of Social Service Research 34(3): 87-98.

Kish Z (2009) "My FEMA People": Hip-Hop as disaster recovery in the Katrina diaspora. American Quarterly 61(3): 671-692.

Kruks-Wisner G (2011) Seeking the local state: gender, caste, and the pursuit of public services in post-tsunami India. World Development 39(7): 1143-1154.

Kushwaha P (2018) Conflicting paradigms and the danger discourse: Re-thinking Indian disaster management framework in the Post-tsunami Era. In: Reddy S (ed) The Asian Tsunami and Post-Disaster Aid, Springer Singapore, pp271-287.

Le Mentec K and Zhang Q (2017) Heritagization of disaster ruins and ethnic culture in China: Recovery plans after the 2008 Wenchuan earthquake. China Information 31(3): 349_ 370.

Lin C and McSweeney J (eds) (2010) Representation and Contestation: Cultural Politics in a Political Century. Rodopi.

Lindahl C (2012) Legends of Hurricane Katrina: The right to be wrong, survivor-to-survivor storytelling, and healing. The Journal of American Folklore 125(496): 139-176.

Linton J (2017) A natural response to a natural disaster: The art of crisis in Nepal. Canadian Art Therapy Association Journal 30(1): 31-40.

Logan W (2015) Bushfire catastrophe in Victoria, Australia: Public record, accountability, commemoration, memorialization and heritage protection. National identities 17(2): 155174.

Luig U (ed) (2012) Negotiating disasters: Politics, representations, meanings. Frankfurt: Peter Lang.

Lyons M (2009) Building back better: The large-scale impact of small-scale approaches to reconstruction. World Development, 37(2), 385-398.

Maxwell DG and Walker P (2014) Shaping the Humanitarian World. Routledge.

McGeehan KM and Baker CK (2017) Religious narratives and their implications for disaster risk reduction. Disasters 41: 258-281.

Miichi K (2016) Playful relief: Folk performing arts in Japan after the 2011 Tsunami. Asian Ethnology 75(1): 139-162.

Misra S, Goswami R, Mondal T and Jana R (2017) Social networks in the context of community response to disaster: Study of a cyclone-affected community in Coastal West Bengal, India. International Journal of Disaster Risk Reduction 22: 281-296.

Mohr E (2014) Posttraumatic growth in youth survivors of a disaster: An arts-based research project. Art Therapy: Journal of the American Art Therapy Association 31(4): 155-162.

Moniruzzaman M (2010) "The ripples changed our lives": Health in post-tsunami Thailand. Disaster Prevention and Management 19: 333-344.

Mooney MF, De Terte I, Johal S, Karanci AN, Gardner D, Collins S, Glavovic B, Huggins TJ, Johnston $L$ and Chambers $R$ (2011). Psychosocial recovery from disasters: A framework informed by evidence. New Zealand Journal of Psychology 40: 26-38.

Mukherji A (2018) Resilience at the margins: Informal housing recovery in Bachhau, India, after the 2001 Gujarat quake. International Journal of Housing Policy 18: 266-289. 
Nisbet MC (2010) Communicating climate change: Why frames matter for public engagement. Environment: Science and Policy for Sustainable Development 51(2): 12 23.

O’Byrne C (2011) Remembering the Piper Alpha Disaster. Historical Reflections 37(2): 90 104.

Pahwa-Gajjar S, Jain G, Michael K and Singh C (2019) Entrenched vulnerabilities: Evaluating climate justice across development and adaptation responses in Southern India. In: Bhavnani K-K, Foran J, Kurian P and Munshi D (eds) Climate Futures: ReImagining Global Climate Justice. London: Zed Books.

Paulmann J (2013) Conjunctures in the history of international humanitarian aid during the twentieth century. Humanity: An International Journal of Human Rights, Humanitarianism, and Development 4(2): 215-238.

Perera-Mubarak KN (2013) Positive responses, uneven experiences: Intersections of gender, ethnicity, and location in post-tsunami Sri Lanka. Gender, Place and Culture 20: 664-685.

Puleo T (2014) Art-making as place-making following disaster. Progress in Human Geography 38(4): 568-580.

Raju E (2013) Housing reconstruction in disaster recovery: A study of fishing communities post-tsunami in Chennai, India. PLoS Currents 5.

Ramírez P and Taylor WB (2013) Out of Tlatelolco's ruins: patronage, devotion, and natural disaster at the shrine of Our Lady of the Angels, 1745-1781. Hispanic American Historical Review 93(1): 33-65.

Ray-Bennett NS (2006) Caste, class and gender: Multiple disasters and women-headed households in an Oriya Village. (PhD thesis, Warwick University, UK).

Ray-Bennett NS (2009) Multiple disasters and policy responses in pre-and postindependence Orissa, India. Disasters 33(2): 274-290.

Richardson BK and Maninger L (2016) "We were all in the same boat": An exploratory study of communal coping in disaster recovery. Southern Communication Journal 81: 107122.

Rivera-Santana C (2020) Aesthetics of disaster as decolonial aesthetics: Making sense of the effects of Hurricane María through Puerto Rican contemporary art. Cultural Studies 34(3): 341-362.

Ruaida Abbas S and Sulman J (2016) Nondeliberative crisis intervention in disaster zones: Social group work using guided artwork with child survivors. Social Work with Groups 39(2-3): 118-128.

Santha SD (2018) Social interfaces in disaster situations: Analyzing rehabilitation and recovery processes among the fisherfolk of Tamil Nadu after the tsunami in India. In: Reddy S (ed) The Asian Tsunami and Post-Disaster Aid, Springer Singapore, pp6578.

Schipper ELF (2010) Religion as an integral part of determining and reducing climate change and disaster risk: An agenda for research. In: Voss M (ed) Der Klimawandel Sozialwissenschaftliche Perspektiven, Wiesbaden: VS Verlag für Sozialwissenschaften, 377-393.

Schwab J (2014) Planning for post-disaster recovery: Next generation. American Planning Association.

Scott M (2014) Media and development. Zed Books Ltd.

Sharma S (2014) Indian media and the struggle for justice in Bhopal. Social Justice 41(1/2): $146-168$.

Shinde KA (2017) Disruption, resilience, and vernacular heritage in an Indian city: Pune after the 1961 floods. Urban Studies 54: 382-398.

Simpson E and Corbridge S (2006) The geography of things that may become memories: The 2001 earthquake in Kachchh-Gujarat and the politics of rehabilitation in the prememorial era. Annals of the Association of American Geographers, 96(3), 566-585.

Simpson, E., and M. de Alwis, 2008: Remembering natural disaster: Politics and culture of memorials in Gujarat and Sri Lanka. Anthropology Today 24: 6-12. 
Stern G (2007) Can God Intervene?: How Religion Explains Natural Disasters. Greenwood Publishing Group.

Sou G (2017) Trivial pursuits? Serious (video) games and the media representation of refugees. Third World Quarterly, 39(3): 510- 526.

Sou G (2019) Sustainable resilience? Disaster recovery and the marginalisation of sociocultural needs and concerns. Progress in Development Studies 19(2): 144-159.

Sovacool BK, Tan-Mullins M and Abrahamse W (2018) Bloated bodies and broken bricks: Power, ecology, and inequality in the political economy of natural disaster recovery. World Development 110: 243-255.

Tebboth MGL (2013) Understanding intractable environmental policy conflicts: The case of the village that would not fall quietly into the sea. The Geographical Journal 180(3): 224-235.

Tewathia N, Kamath A and llavarasan PV (2020) Social inequalities, fundamental inequities, and recurring of the digital divide: Insights from India. Technology in Society, 61, 101251.

Thomas T, Ott JS and Liese H (2011) Coproduction, participation and satisfaction with rehabilitation services following the 2001 earthquake in Gujarat, India. International Social Work 54: 751-766.

Tierney K, Bevc C and Kuligowski E (2006) Metaphors matter: Disaster Hurricane Katrina. The Annals of the American Academy of Political and Social Science 604: 57-81.

Tierney K and Oliver-Smith A (2012) Social dimensions of disaster recovery. International Journal of Mass Emergencies and Disasters 30(2): 123-146.

Titz A, Cannon T and Krüger F (2018) Uncovering 'community': Challenging an elusive concept in development and disaster related work. Societies 8(3): 71.

UNDRR (2019) Global Assessment Report on Disaster Risk Reduction, United Nations Office for Disaster Risk Reduction, Geneva, Switzerland.

Ware V-A and Dunphy K (2020) How do arts programs contribute in international development? A systematic review of outcomes and associated processes. Progress in Development Studies 20(2): p140-162.

WHO (2013) Building Back Better: sustainable mental health care after emergencies. World Health Organization, Geneva, Switzerland.

Wilkinson E, Twigg J and Few R (2018) Building back better: A resilient Caribbean after the 2017 hurricanes. ODI Briefing Paper. London: Overseas Development Institute.

Wisner B, Blaikie P, Cannon T and Davis I (2004) At risk: Natural hazards, people's vulnerability and disasters. London: Routledge.

Xu B (2016) Moral performance and cultural governance in China: The compassionate politics of disasters. The China Quarterly 226: 407-430.

Zavar EM and Schumann RL (2019) Patterns of disaster commemoration in long-term recovery. Geographical review 109(2): 157-179.

Zerrudo R (2016) Theater of disaster: Folk stories as vehicles for healing and survival. Teaching Artist Journal 14(3): 161-170.

Zhang Q (2016) Disaster response and recovery: Aid and social change. Annals of Anthropological Practice 40(1): 86-97. 